\title{
THE HARDNESS OF HIGH-ENTROPY COATINGS OBTAINED BY THE METHOD OF MECHANICAL ALLOYING
}

\author{
Yurov V.M., Makhanov K.M. \\ E.A. Buketov Karaganda University, Karaganda, Kazakhstan, exciton@list.ru
}

\begin{abstract}
The article shows that the hardness of most stainless steels is 2-3 times less than high-entropy coatings, which shows the prospect of their use as parts of various industrial structures. Microhardness of metallic glasses, which have a defect-free base, and do not differ from high-entropy coatings. In the article, an equation is obtained that shows that the destruction of the coating is proportional to the surface energy and inversely proportional to the Gibbs energy. For stainless steels, the surface energy is about the same as for high-entropy coatings. The Gibbs energy of high-entropy coatings is 2 times higher than that of stainless steels, which leads to a high hardness of high-entropy coatings, which is observed experimentally.
\end{abstract}

Keywords: microhardness, high-entropy coating, steel, surface energy, destruction of the coating, nanostructure.

\section{Introduction}

This work is a continuation of works [1-3], where the properties of functional and high-entropy coatings are considered. In high-entropy alloys, as a result of the effect of intense mixing, the entropy contribution increases, which stabilizes the formation of a solid solution with a simple structure [4-6]. Based on Boltzmann's hypothesis about the relationship between entropy and system complexity, the configurational change in entropy $\Delta \mathrm{S}_{\text {conf }}$ during the formation of a solid solution of $\mathrm{n}$ elements with equiatomic content can be calculated using the following formula:

$$
\Delta \mathrm{S}_{\mathrm{conf}}=-\mathrm{R} \ln (1 / \mathrm{n})=\mathrm{R} \ln (\mathrm{n}),
$$

where $\mathrm{R}$ is the universal gas constant, $\mathrm{n}$ is the number of mixing elements.

At $n=5, \Delta S_{\text {conf }}=1.61 \mathrm{R}$ approaches the value of the melting entropy of most intermetallics (about $2 \mathrm{R}$ ). However, it was later shown that a high entropy of mixing is not a necessary condition for the formation of a single-phase solid solution, but the very term for the name of such an alloy remains in use.

\section{Analysis of publications}

First of all, we will mention only those publications that relate to the latest advances in the field of highentropy coatings. Articles [7-9] provide a review of high-entropy materials with their unique structural characteristics, individual chemical composition and functional properties. They are generating increasing interest in the fields of environmental science and renewable energy technology. Despite all the (potential) advantages inherent in high-entropy materials over conventional alloys, oxides and other compounds, there are some obvious problems associated with their practical use in the energy sector. Rational design of highentropy materials is very difficult at present. One possibility is an approach using theoretical machine learning methods to design high-entropy materials with the desired properties. From an experimental point of view, a more efficient way would be to select a benchmark of the model and gradually add or replace new elements to change the configuration entropy of the system. Another general strategy is to subdivide components into subcategories according to their roles in the system, and then add or replace the selected item with other similar items in each category.

Article [10] provides a detailed overview of thermal spray coatings. These methods are opposed to the methods of laser cladding and surface alloying for the synthesis of thick high-entropy coatings. The article [11] provides an overview of high-entropy coatings in the aerospace industry. Figure 1 shows the hardness of high-entropy alloys and compounds. based on refractory metals. Modeling showed that materials based on refractory high-entropy alloys, their carbides, borides and nitrides showed a wide spread in the calculated hardness, which ranged from $4.1 \mathrm{GPa}$ to $21.3 \mathrm{GPa}$. The materials and methods described in the article can 
give a positive result for applications in the aerospace industry: sectors that are associated with high loads (frames, chassis, shafts, etc.) and extremely high temperatures (engines, propulsion systems).

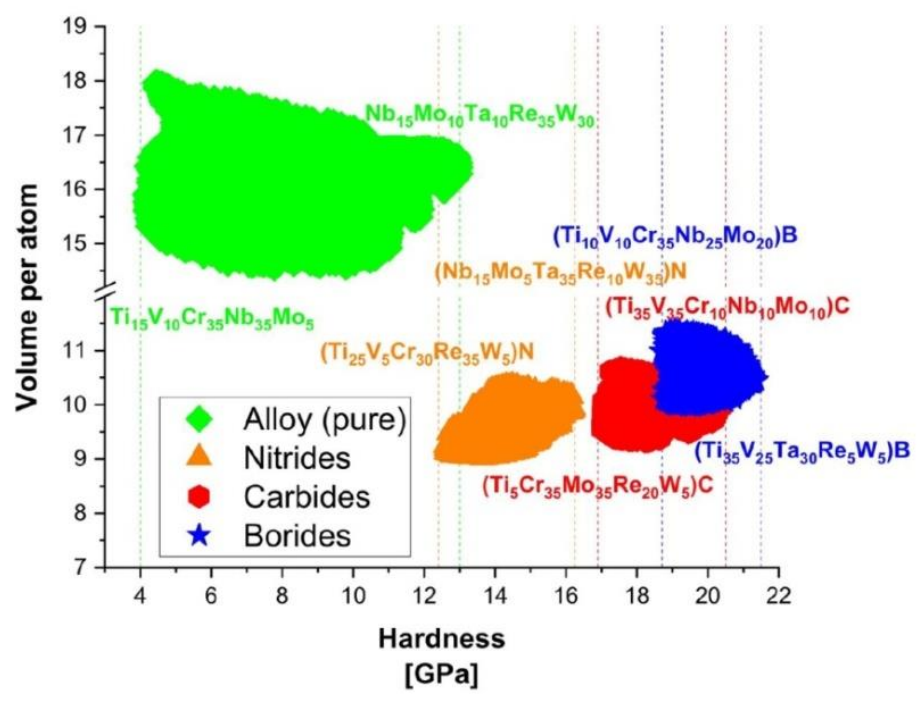

Fig.1. Graphical representation of predicted hardness of high-entropy alloys and compounds based on the refractory metals: dotted lines represent the maximum and minimum hardness [11].

Articles [12-14] provide an overview in the field of high-entropy nitride materials, with particular attention to coatings in which the phases of the solid solution with the formation of simple crystal structures. The latter will include advanced data processing with artificial intelligence and machine learning to aid in the assessment large common datasets from experimental and theoretical work. This change in methodology will be a challenge but will be necessary to fully realize the potential of high-entropy nitride materials. Article [15] is devoted to a review of high-entropy ceramics.

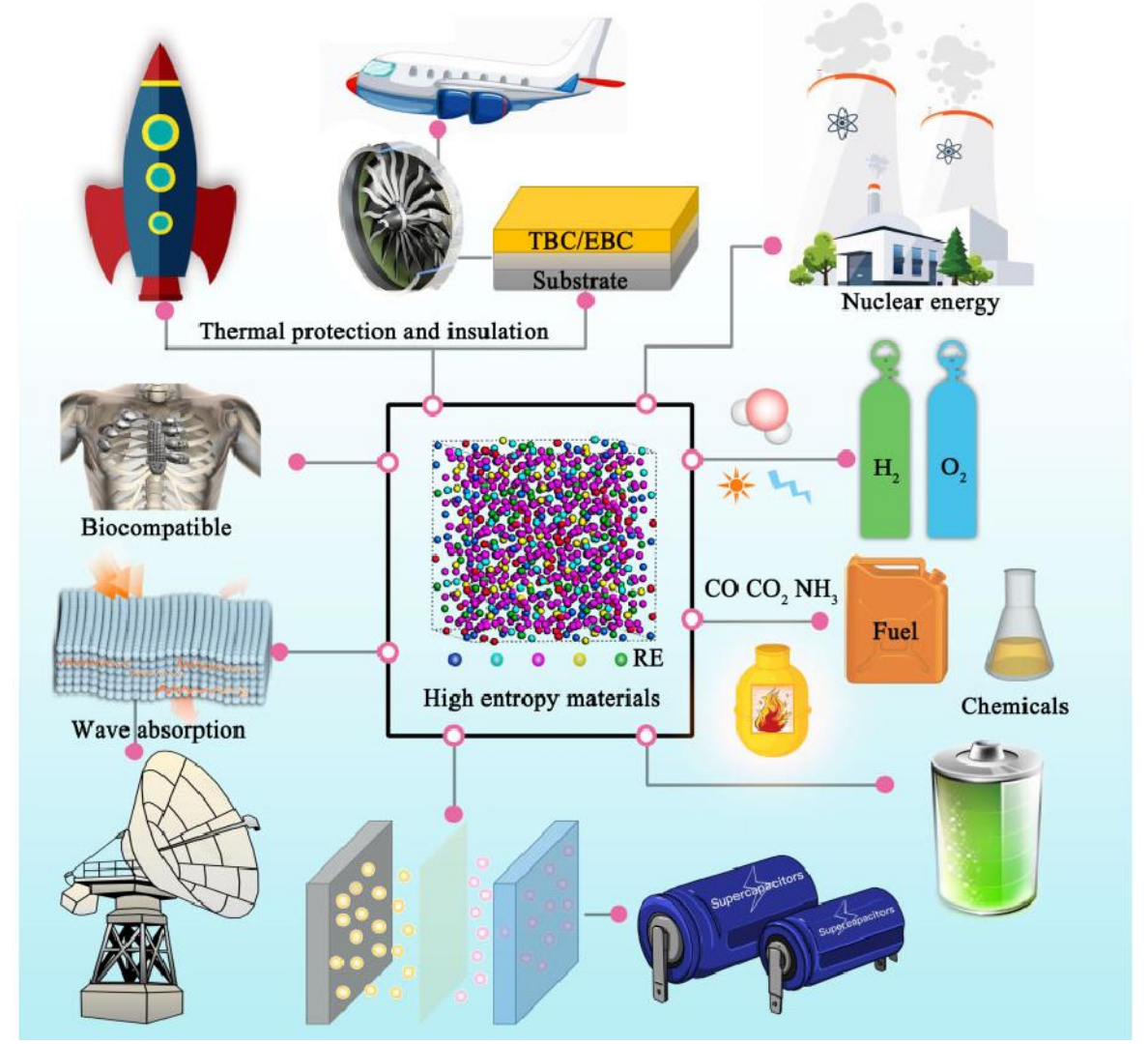

Fig.2. Prospective applications of HECs covering from ultrahigh-temperature structural to energy and catalytic functional applications, [15]. 
In addition to hardening and low thermal conductivity, which has already been found in high-entropy alloys, new properties such as colossal dielectric constant, superionic conductivity, strong anisotropic coefficient of thermal expansion, strong absorption of electromagnetic waves, etc. have been found in highentropy ceramics. In response to the rapid development in this nascent field, this article provides a comprehensive overview of design features, theoretical methods for predicting stability and properties, machining routes, new properties, and promising applications of high-entropy ceramics (Figure 2).

The main goal of this work is to experimentally investigate the microhardness of high-entropy coatings and propose a model that will allow, within the framework of the energy theory, to explain the observed effects.

\section{Objects and experimental technique}

High-entropy (HEC) coatings of the following composition were used as objects of research: TiNiZrCuCr, CrFeNiTiZrCu, TiFeCuAlSn, AlCrNiTiZrCu, PbCrNiTiZrCu, CrNiTiZrAlCu. The coatings were obtained by sputtering magnetron targets of the above compositions on $12 \mathrm{X} 13$ steel using an NNV6.6I1 setup.. These targets were manufactured by us by the method of mechanical alloying [16], in contrast to cast targets obtained by the metallurgy method. Moreover, after annealing in a vacuum chamber, the samples became nanostructured. Fig. 3a shows, as an example, a sample under study with an HEC-coating, in Fig. 3b of their SEM image of the HEC-coating, and in Fig. 3c diagram of the formation of nanostructured HEC-coatings [17].The roughness of the coating, as an example, measured with the atomic force microscope (AFM) JSPM-5400, is also negligible (Figure 4) [18].

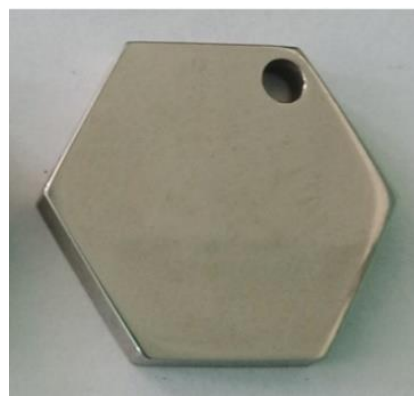

a)

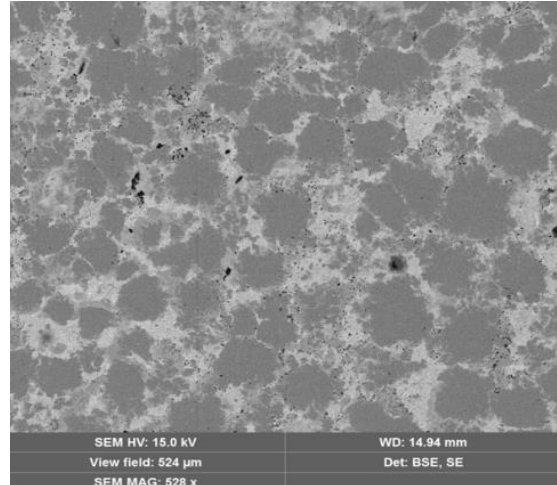

b)

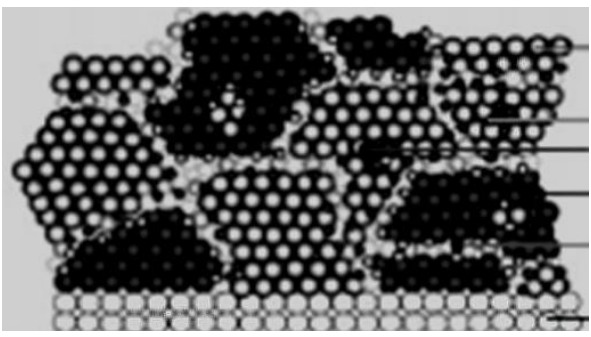

c)

Fig.3. A sprayed sample with an HEC-coating (a), an REM image of an HEC-coating (b), a diagram of the formation of nanostructured coatings of an HEC-coating [17].

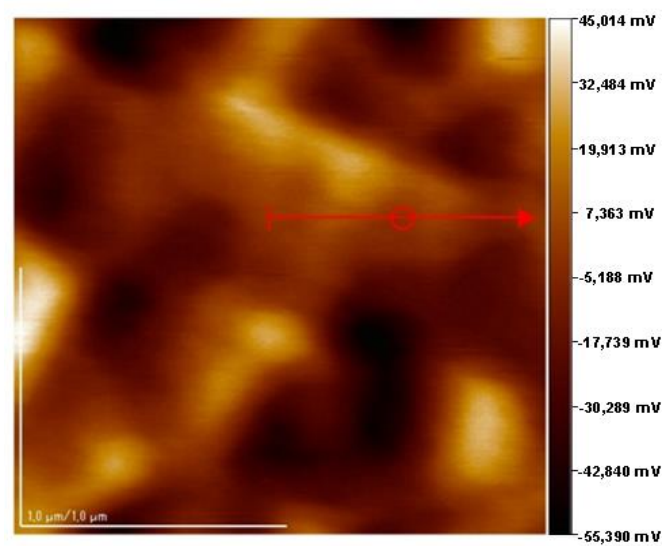

a)

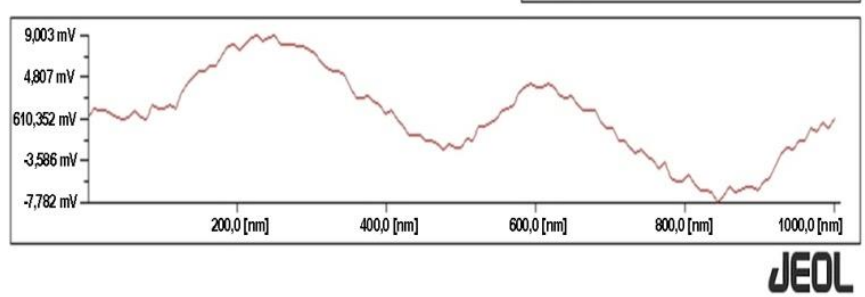

b)

Fig.4. AFM image of TiNiZrCuCr (a) and its roughness (b), [18]. 
X-ray fluorescence spectroscopy (XPS) (Figure 5), as an example, shows that the investigated coatings form high-entropy coatings in the composition from 5 to 35 at. \%. Figure 6 shows the distribution of elements in the coverage, which shows that the elements are evenly distributed.

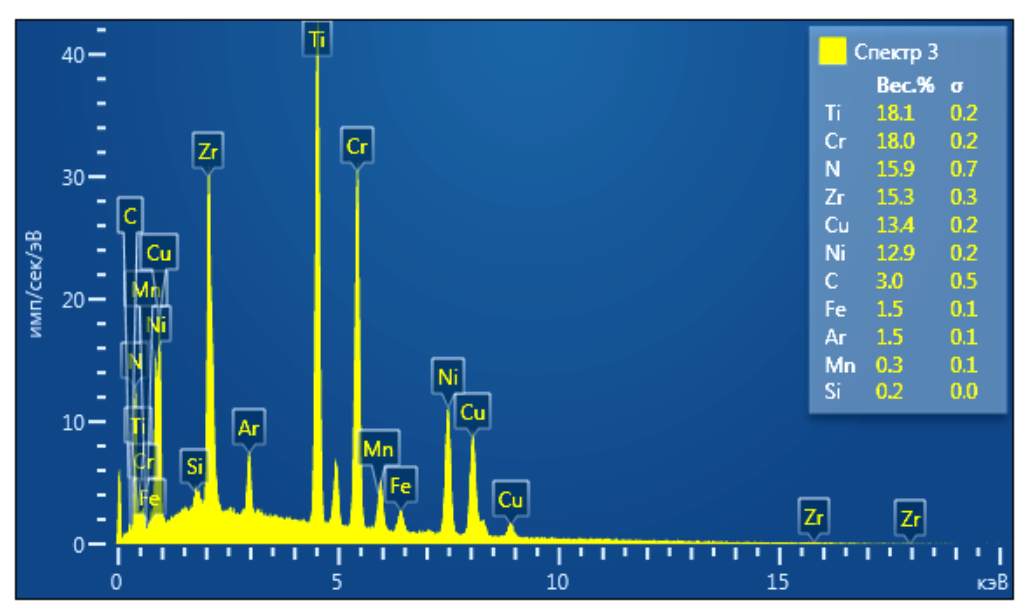

a)

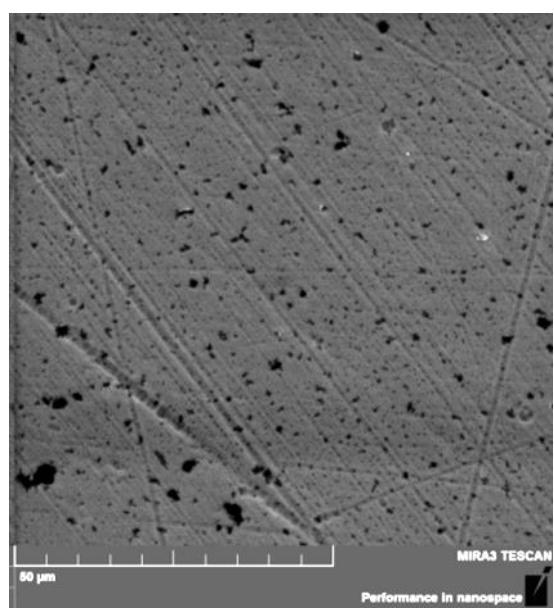

b)

Fig.5. XPS TiNiZrCuCr (a), SEM image of TiNiZrCuCr (b)

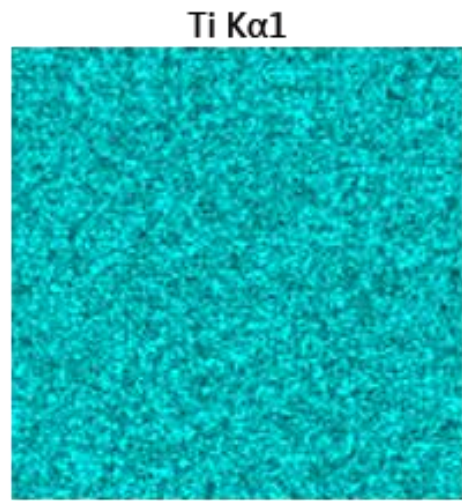

$\longdiv { 2 5 \mu \mathrm { m } }$

$\mathrm{Cu} \mathrm{K} \alpha 1$

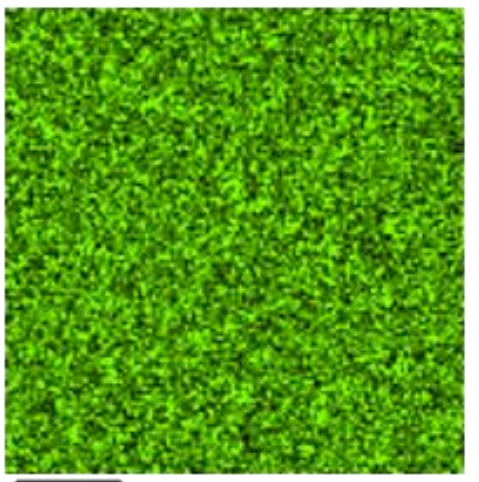

$\sqrt{25 \mu \mathrm{m}}$

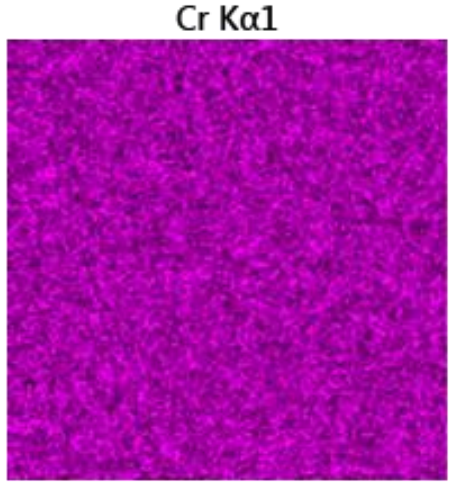

$\longdiv { 2 5 \mu \mathrm { m } }$

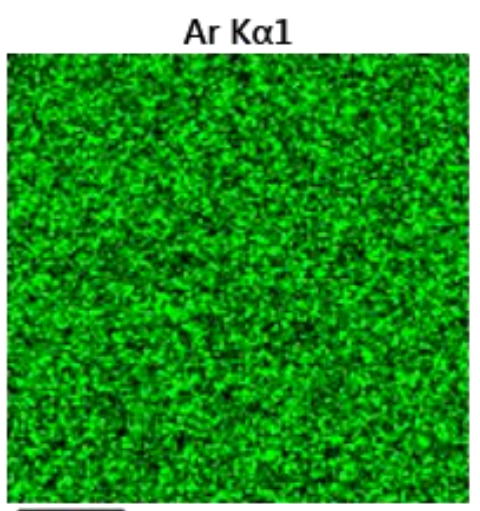

$\longdiv { 2 5 \mu \mathrm { m } }$
$\operatorname{Zr} \operatorname{L} \alpha 1$

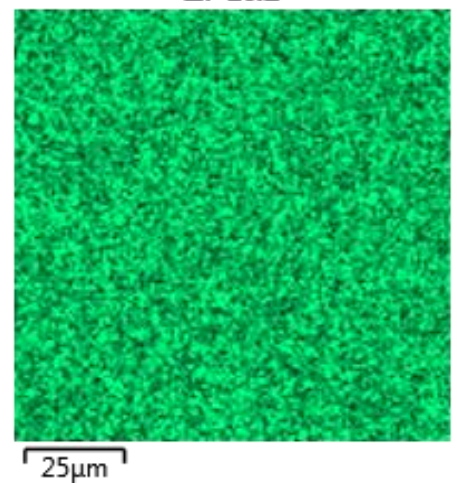

Ni K $\alpha 1$

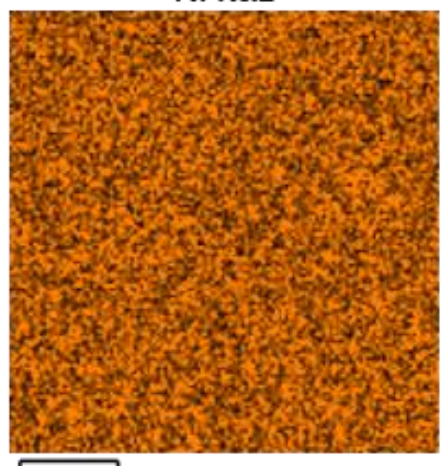

$\longdiv { 2 5 \mu \mathrm { m } }$

Fig.6. Distribution of TiNiZrCuCr elements deposited on $12 \mathrm{X} 13$ steel in argon

Such a distribution occurs in the coating due to a diffusion process that occurs during thermal annealing of the magnetron target in a vacuum chamber for 3-5 hours. We used an HVS-1000A microhardness tester to measure the coatings (Figure 7). This instrument is designed using the latest advances in mechanics, optics, electronics and computer technology to test the hardness of metallic and non-metallic materials, especially small parts or thin hardened layers. 


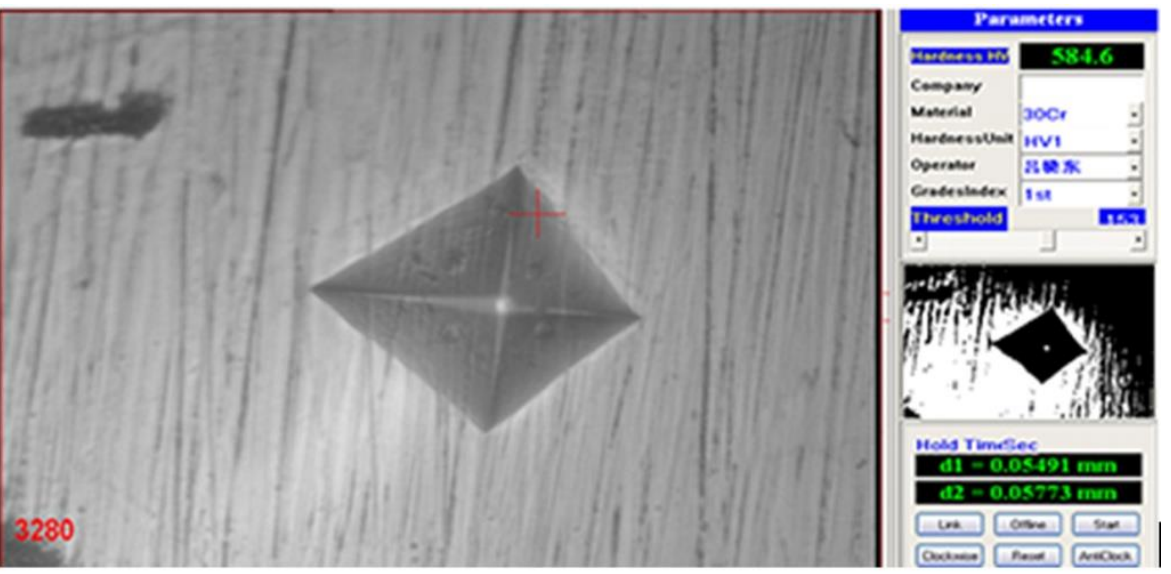

Fig.7. Measurement of coatings on a HVC-1000A microhardness tester

\section{Research results and their discussion}

Using the above methods, the table of experimental values can be given. Table 1 shows that pentaatomic alloys have higher hardness. Hexaatomic alloys have slightly less hardness.

Table 1. Experimental properties of high-entropy coatings (HEC) and metallic glasses (MG) [19]

\begin{tabular}{|c|c|c|c|}
\hline $\mathrm{HEC}$ & $\mu, \mathrm{HV}$ & $\mathrm{MG}$ & $\mu, \mathrm{HV}$ \\
\hline $\mathrm{CrTiNiZrCu}$ & 890 & $\mathrm{Fe}_{78} \mathrm{Mo}_{2} \mathrm{~B}_{20}$ & 1015 \\
\hline TiFeCuAlSn & 700 & $\mathrm{Fe}_{40} \mathrm{Ni}_{40} \mathrm{P}_{14} \mathrm{~B}_{6}$ & 640 \\
\hline $\mathrm{CrFeNiTiZrCu}$ & 740 & $\mathrm{Fe}_{78} \mathrm{P}_{13} \mathrm{C}_{7}$ & 760 \\
\hline $\mathrm{AlCrNiTiZrCu}$ & 585 & $\mathrm{Fe}_{78} \mathrm{Si}_{10} \mathrm{~B}_{12}$ & 890 \\
\hline $\mathrm{PbCrNiTiZrCu}$ & 560 & $\mathrm{Ni}_{75} \mathrm{Si}_{8} \mathrm{~B}_{17}$ & 860 \\
\hline $\mathrm{CrNiTiZrAlCu}$ & 530 & $\mathrm{Co}_{75} \mathrm{Si}_{15} \mathrm{~B}_{10}$ & 910 \\
\hline
\end{tabular}

Let us compare the hardness of stainless steels [20] with the hardness of high-entropy coatings from Table 2. Table 2 shows that the hardness of most stainless steels is 2-3 times less than high-entropy coatings. This opens up the prospect of using high-entropy coatings on parts of various industrial structures.

Table 2. Hardness of stainless steels [20]

\begin{tabular}{|c|c|c|c|}
\hline Steel & $\mu, \mathrm{HV}$ & Steel & $\mu, \mathrm{HV}$ \\
\hline $12 \mathrm{X} 13$ & $121-187$ & $08 \mathrm{X} 17 \mathrm{~T}$ & 372 \\
\hline $40 \mathrm{X} 13$ & $143-229$ & $10 \mathrm{X} 17 \mathrm{H} 13 \mathrm{M} 2 \mathrm{~T}$ & 200 \\
\hline $08 \mathrm{X} 18 \mathrm{H} 10$ & 170 & $12 \mathrm{X} 18 \mathrm{H} 10 \mathrm{~T}$ & 179 \\
\hline
\end{tabular}

For comparison, Table 1 shows the microhardness of metal glasses, which have a defect-free base and do not differ much from high-entropy coatings [19].

What is the reason for this difference?

To determine the resistivity of high-entropy alloys, an experimental setup was assembled and $\rho$ (Ohm $\mathrm{m})$ was measured [21]. It turned out that the specific resistance of the investigated high-entropy alloys lies in the range (5-7) $10^{-8} \mathrm{Ohm} \mathrm{m}$, i.e. slightly different from $\rho_{\mathrm{W}}=5.510^{-8} \mathrm{Ohm} \mathrm{m}$. According to Ohm's law, the current density in metals is:

$$
j=e n v=1 / \rho \cdot E
$$

Whence for the concentration of electrons we have the expression:

$$
\mathrm{n}=1 / \mathrm{ev} \rho \cdot \mathrm{E}_{\mathrm{F}} \text {, }
$$


where the electron charge $\mathrm{e}=1.6021766210^{-19} \mathrm{~K}$ c; resistivity $\rho=510^{-8} \mathrm{Ohm} \mathrm{m}$ : average electron velocity $\mathrm{v}_{\mathrm{Cu}}=7410^{-6} \mathrm{~m} / \mathrm{s}$; the Fermi energy $\mathrm{E}_{\mathrm{F}}=1410^{-19} \mathrm{~J}$. Thus, the concentration of conduction electrons in the alloy near the Fermi level is $\mathrm{n} \approx 310^{18}$.

We will consider the question of the response of a subsystem of $n$ electrons in high-entropy alloys to an external action during friction from the standpoint of nonequilibrium statistical thermodynamics. The electrons in the alloy will be considered as a system of non-interacting particles immersed in a thermostat. The thermostat is a metal alloy minus $n$ "free" electrons. Quantum transitions during friction, caused by the interaction of a system of electrons with a thermostat, will be dissipative (with probability P), in contrast to the interaction during friction (with probability F). Dissipative processes lead to the fact that the secondary field (system response) is always less than the primary one, which causes the formation of heat during friction. We will assume that the electron subsystem exchanges only energy with the thermostat. Then the corresponding ensemble of particles will be canonical. In this case, the expression for the statistical entropy has the form:

$$
S=-k \sum_{i} f_{i} \ln f_{i}
$$

where $\mathrm{f}_{\mathrm{i}}$ is the distribution function; $\mathrm{k}$ is Boltzmann's constant.

Differentiating (3) with respect to time and transforming, we obtain:

$$
\frac{\mathrm{dS}}{\mathrm{dt}}=\frac{\mathrm{k}}{2} \sum_{\mathrm{i}, \mathrm{j}}\left(\operatorname{lnf}_{\mathrm{i}}-\operatorname{lnf}_{\mathrm{j}}\right)\left(\mathrm{P}_{\mathrm{ij}} \mathrm{f}_{\mathrm{i}}-\mathrm{P}_{\mathrm{ji}} \mathrm{f}_{\mathrm{j}}\right)
$$

where $P_{i j}$ is the probability of transition from the initial $i$ (with energy $E_{i}$ ) to the state $j$ excited by friction (with energy $\mathrm{E}_{\mathrm{j}}$ ). For dissipative processes, the principle of detailed balance has the form:

$$
\frac{g_{i} P_{i j}}{g_{j} P_{j i}}=e^{\frac{E_{j}-E_{i}}{k T}},
$$

where $g_{i}, g_{j}$ are statistical weights for the levels $E_{i}$ and $E_{j}$.

Finally, in [22], we obtained the following formula for the destruction efficiency $\eta$ of a metal coating:

$$
\eta=\frac{k^{2} \Delta t}{2 \Delta S \cdot \tau} \cdot T \cdot \frac{E_{m}}{G^{0}} \cdot \bar{n}=\text { const } \cdot T \cdot \frac{\sigma \cdot S}{\tau \cdot G^{0}} \cdot \bar{n}
$$

Equation (6) describes the destruction of the coating $\eta$ proportional to $\mathrm{k}$ - the Boltzmann constant, the change in entropy $\Delta \mathrm{S}$ and the time of motion during friction $\Delta \mathrm{t}$, the work of friction forces $\mathrm{E}_{\mathrm{m}}=\mathrm{A}=\sigma \mathrm{S}$, the concentration of electrons $n$ near the Fermi level, surface energy $\sigma$, contact area $S$ and vice versa is proportional to the relaxation time $\tau$ and the Gibbs energy $G^{0}$ of the thermostat.

The difference in the destruction of high-entropy coatings from stainless steels is in the analysis of equation (6). It follows from this equation that the destruction of the coating $\eta$ is proportional to the surface energy $\sigma$ and inversely proportional to the Gibbs energy $G^{0}$, that is, the condition $\eta \rightarrow \sigma / G^{0} \rightarrow$ min must be satisfied. Since the surface energy $\sigma_{\mathrm{st}}$ for stainless steels is approximately equal to the surface energy of highentropy coatings $\sigma_{\mathrm{n}}$, that is, $\sigma_{\mathrm{st}} \approx \sigma_{\mathrm{n}}$. But the Gibbs energy of stainless steels is approximately $1 \mathrm{R}$ and for high-entropy coatings it is approximately $2 \mathrm{R}$, that is, $\eta \rightarrow \sigma / \mathrm{G}^{0} \rightarrow 1 / 2$. Failure of the coating $\eta$ can be calculated as the ratio of the hardness of stainless steels to the hardness of high-entropy coatings using the formula $\eta \rightarrow \mu_{\mathrm{st}} / \mu_{\mathrm{n}}$. This gives the following result $-\eta \rightarrow 1 / 2$, which is observed experimentally (Tables 1 and 2). In fig. 8a (according to equation 1) shows an increase in the entropy of mixing with an increase in the number of elements for equimolar alloys.

It can be seen that the entropy of mixing for the phases of the solid solution increases from a small value for conventional alloys to a large value for high-entropy alloys of the composition [4]. Based on the effect of entropy of mixing, it is possible to divide the variety of alloys into three fields, as shown in Fig. 8b. Low entropy alloys are traditional alloys. High-entropy alloys are alloys with at least five basic elements. 
Medium entropy alloys are alloys with $2 \ldots 4$ basic elements. The high-entropy effect of activation of the formation of a disordered solid phase occurs essentially in the field of high-entropy alloys and should be present to a lesser extent in medium-entropy alloys. Stabilization of a simple solid solution phase is important for the microstructure and properties that can be obtained in these materials [4-6].

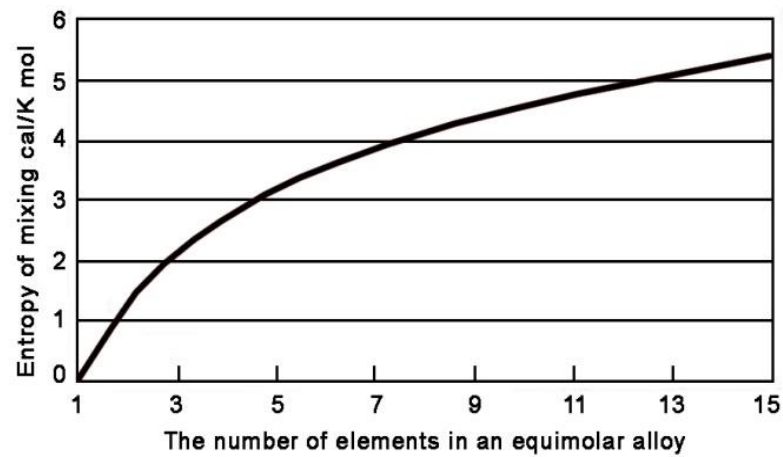

a)

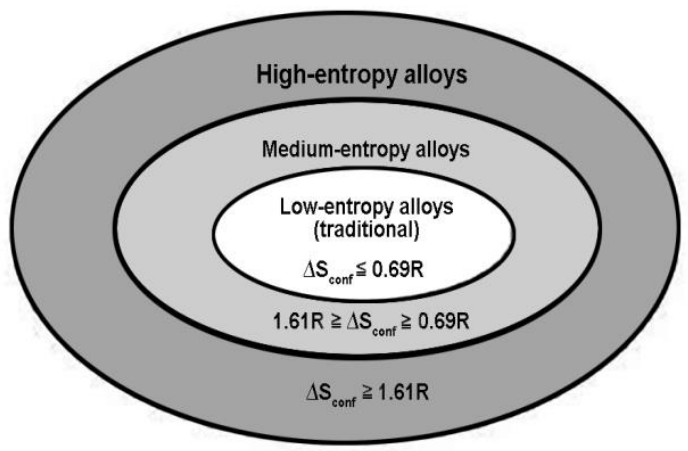

b)

Fig.8. The increase in the entropy of mixing to the number of elements in equimolar alloys in a disordered state (a), the division of the world of alloys by the entropy of mixing (b) [4].

\section{Conclusion}

High-entropy coatings TiNiZrCuCr, CrFeNiTiZrCu, TiFeCuAlSn, AlCrNiTiZrCu, PbCrNiTiZrCu, CrNiTiZrAlCu were investigated in this work. Such coatings were obtained on an NNV-6.6I1 setup by sputtering magnetron targets of the above compositions. These targets were manufactured by mechanical alloying methods, in contrast to cast targets obtained by metallurgy. Moreover, after annealing in a vacuum chamber, the samples became nanostructured.

We have shown experimentally and theoretically that the destruction of high-entropy coatings is proportional to the surface energy $\sigma$ and inversely proportional to the Gibbs energy $\mathrm{G}^{0}$. Failure of the coating $\eta$ can be calculated as the ratio of the hardness of stainless steels to the hardness of high-entropy coatings using the formula $\eta \rightarrow \mu_{\mathrm{st}} / \mu_{\mathrm{n}}$. This gives the following result $-\eta \rightarrow 1 / 2$, which is observed experimentally.

\section{Acknowledgments}

The work was carried out under the program of the Ministry of Education and Science of the Republic of Kazakhstan. Grants No. 0118 RK000063 and No. F.0781.

\section{REFERENCES}

1 Guchenko S.A, Zavatskaya O.N., Yurov V.M., Kasymov S.S., Laurinas V.Ch. Fractal structure of multielement coating. Eurasian Physical Technical Journal. 2018, Vol. 15, No.1 (29), pp. 8-17.

2 Eremin E.N., Yurov V.M., Guchenko S.A. Wear resistance and tribological properties of high entropy coatings CrNiTiZrCu. Eurasian Physical Technical Journal. 2020, Vol.17, No.1 (33), pp. 13-18.

3 Yurov V.M., Guchenko S., Salkeeva A.K., Kusenova A.S. Nitrogening hydraulic cylinder rods. Eurasian Physical Technical Journal. 2020, Vol.17, No.1 (33), pp. 25-30.

4 Yeh J.-W., Chen S.-K., Lin S.-J., et al. Nanostructured High-Entropy Alloys with Multiple Principle Elements: Novel Alloy Design Concepts and Outcomes. Advanced Engineering Materials, 2004, Vol. 6, No. 8, pp. 299303.

5 Yeh J.W., Chen Y.L., Lin S.J. High-entropy alloys - a new era of exploitation. Materials Science Forum. 2007, Vol. 560. - P. 1-9.

6 Wang Y.P., Li B.Sh., Heng Zh.F. Solid Solution or Intermetallics in a High-Entropy Alloy. Advanced Engineering Materials, 2009, Vol. 11, No. 8, pp. 641-644.

7 Vyas A., Menghania J., Natub H. Metallurgical and Mechanical Properties of Laser Cladded $\mathrm{AlFeCu}$ CrCoNi-WC10.High Entropy Alloy Coating. IJE TRANSACTIONS A: Basics. 2020, Vol. 33, No. 7, pp. 1397-1402

8 Yanjiao Ma, Yuan Ma, Qingsong Wang et al. High-entropy energy materials: challenges and new opportunities. Energy Environ. Sci., 2021, Vol. 14, pp. 2883-2905.

9 Sharma A. High Entropy Alloy Coatings and Technology. Coatings, 2021, Vol. 11, pp. 372-388.

10 Meghwal A., Anupam A., Murty B.S., Berndt C.C., Kottada R.S., Ming Ang A.S. Thermal Spray HighEntropy Alloy Coatings: A Review. Journal of Thermal Spray Technology, 2020, pp. 1-38. 
11 Postolnyi B., Buranich V., Smyrnova K. et al. .Multilayer and high-entropy alloy-based protective coatings for solving the issue of critical raw materials in the aerospace industry. IOP Conf. Series: Materials Science and Engineering, 2021, 1024, pp. 012009

12 Cheng-Yu He, Xiao-Li Qiu, Dong-Mei Yu et al. Greatly enhanced solar absorption via high entropy ceramic AlCrTaTiZrN based solar selective absorber coatings. Journal of Materiomics. 2021, Vol. 7, pp. 460-469.

13 Lewin E. Multi-component and high-entropy nitride coatings. A promising field in need of a novel approach. Journal of Applied Physics, 2020, Vol. 127, pp. 220901.

14 Mishra A. Friction Stir Welding/Processing of High Entropy Alloys (HEAs). Welding Technology Review, 2021, Vol. 93(1), pp. 27-33.

15 Xiang H., Xing Y., Dai F., Wang H. et al. High-entropy ceramics: Present status, challenges, and a look forward. Journal of Advanced Ceramics. 2021, Vol. 10(3), pp. 385-441.

16 Yurov V.M., Guchenko S.A., Tvardovsky A.N. Two targets for magnetron deposition of high-entropy coatings. Trends in the development of science and education, 2020, No. 60(1), pp. 28-34.

17 Pogrebnyak A.D., Bagdasaryan A.A. Pink A.V., Dyadyura K.A. Multicomponent nanocomposite coatings with adaptive behavior in surface engineering. Uspekhi fizicheskikh nauk. 2017, Vol. 187, No. 6, pp. 629-652.

18 Yurov V.M., Guchenko S.A., Makhanov K.M. Atomic force microscopy of high-entropy coatings. International Journal of Applied and Fundamental Research. 2020, No. 4, pp. 62-67.

19 Cheng Y.Q., Ma E. Atomic-level structure and structure-property relationship in metallic glasses. Progress in Materials Science. 2011, Vol. 56, pp. 379-473.

20 Povolotskiy D.Ya., Gudim Yu.A. Stainless steel production. - Chelyabinsk, 1998. - 236 p.

21 Yurov V.M., Guchenko S.A. Electrical conductivity of seven-atom high-entropy alloys. Interuniversity scientific congress "Higher school: scientific research", 2019, Vol. 1, pp. 142-148.

22 Yurov V.M., Guchenko S.A., Zavatskaya O.N. Structure and surface tension of composite coatings. Bulletin of KSU. Physics, 2012, No. 1 (65), pp. 45-53. 